LUIZA BARROS ROZAS

\title{
DIREITO À MORADIA: ÂMBITO, LIMITES E CONTROLE NO ORDENAMENTO JURÍDICO NACIONAL
}

Tese de Doutorado

Orientadora: Professora Associada Dra. Nina Beatriz Stocco Ranieri

UNIVERSIDADE DE SÃO PAULO

FACULDADE DE DIREITO

São Paulo-SP

2016 
LUIZA BARROS ROZAS

\section{DIREITO À MORADIA: ÂMBITO, LIMITES E CONTROLE NO ORDENAMENTO JURÍDICO NACIONAL}

Tese apresentada à Banca Examinadora do Programa de Pós-Graduação em Direito, da Faculdade de Direito da Universidade de São Paulo, como exigência parcial para obtenção do título de Doutora em Direito, na área de concentração Direitos Humanos, sob a orientação da Professora Associada Dra. Nina Beatriz Stocco Ranieri.

UNIVERSIDADE DE SÃO PAULO

FACULDADE DE DIREITO

São Paulo-SP

2016 
Autorizo a reprodução e divulgação total ou parcial deste trabalho, por qualquer meio convencional ou eletrônico, para fins de estudo e pesquisa, desde que citada a fonte.

\section{Rozas, Luiza Barros}

Direito à moradia: âmbito, limites e controle no ordenamento jurídico nacional / Luiza Barros Rozas. -- São Paulo: USP / Faculdade de Direito, 2016.

$217 f+$ anexo.

Orientadora: Profa. Associada Dra. Nina Beatriz Stocco Ranieri. Tese (Doutorado), Universidade de São Paulo, USP, Programa de Pós-Graduação em Direito, Direitos Humanos, 2016.

1. Direitos humanos. 2. Direito à moradia. 3. Função social da propriedade. 4. Políticas públicas urbanísticas. I. Ranieri, Nina Beatriz Stocco. II. Título. 
BANCA EXAMINADORA 
ROZAS, Luiza Barros. Direito à moradia: âmbito, limites e controle no ordenamento jurídico nacional. 2016. 217f. Tese (Doutorado). Faculdade de Direito da Universidade de São Paulo, São Paulo, 2016.

\section{RESUMO}

A presente tese tem por objetivo o estudo do direito à moradia e de sua inserção no ordenamento jurídico, analisando-se seu âmbito, seus limites e seu controle a partir de uma perspectiva de construção de um novo modelo de atuação do Poder Judiciário. Âmbito refere-se à definição, isto é, à busca do significado e da natureza jurídica do direito à moradia. Os limites, por sua vez, referem-se à forma de inserção deste direito em nosso quadro normativo à luz das políticas públicas destinadas à sua efetivação e sistematização no âmbito do pacto federativo. Finalmente, o controle do direito à moradia pelo Poder Judiciário pode se dar tanto pela mediação quanto pela jurisdição. Em países como o Brasil, onde há fortes desigualdades sociais e as instituições democráticas mostram-se ainda frágeis, as demandas levadas aos agentes e órgãos do Estado, dentre os quais estão os do Poder Judiciário, são quantitativas e qualitativamente maiores no que se refere à concretização dos direitos fundamentais. Busca-se, assim, uma reflexão sobre o arcabouço jurídico e as políticas públicas habitacionais vigentes, bem como sobre os mecanismos de utilização deste arcabouço na solução dos conflitos judiciais que chegam aos tribunais. A aplicação do direito à moradia, de acordo com a nova ordem constitucional e a legislação decorrente, ainda está em processo de amadurecimento. Com efeito, nota-se uma dificuldade na resolução de tais conflitos, que demandam por parte do julgador uma nova leitura dos princípios constitucionais, sobretudo o da função social da propriedade, visando a concretização do direito à moradia.

Palavras-chave: Direito à moradia; Função social da propriedade; Habitação, Controle judicial; Políticas públicas urbanísticas. 
ROZAS, Luiza Barros. The right to housing: scope, limits and control, in accordance to the legal framework. 2016. 217p. PhD Thesis, Faculty of Law, University of São Paulo, São Paulo, 2016.

\begin{abstract}
The present thesis provides an overview of the right to housing, its regulation, scope, limits and control, aiming to build a new operating model for the judicial authorities. Scope means conceptualization, that is to say, the meaning and judicial nature of the right to housing. Limits mean the way of insertion of this right in our legal framework, in light of public policies aimed at its effectuation and systematization under the federative pact. Finally, regarding the judiciary powers' control of housing rights, this can take place by either mediation or adjudication. In countries like Brazil, where there are strong social inequalities and democratic institutions are yet fragile, the demands brought to State agents and departments, among which are the judges, are both quantitatively and qualitatively greater concerning the implementation of the fundamental rights. Thus, this work presents the legal framework and current public housing policies in Brazil, as well as the practice of the courts in resolving the judicial conflicts. The implementation of the social right to housing, in accordance to the new constitutional order and ensuing legislation, is still in the process of maturation. In effect, there is a perceptible difficulty in solving such conflicts - which demand a new interpretation of the constitutional principles by the judge, especially in relation to the social function of property.
\end{abstract}

Keywords: Right to housing; Social function of property; Dwelling; Judicial control; Urban public policies. 
ROZAS, Luiza Barros. Diritto all'abitazione: ambito, limiti e controllo nell'ordinamento giuridico nazionale. 2016. 217p. Tesi (Dottorato). Facoltà di Diritto del'Università di São Paulo, 2016.

\section{RIASSUNTO}

La presente tesi ha come obiettivo lo studio del diritto all'abitazione e la sua introduzione nell'ordinamento giuridico, analizzandone l'ambito, i limiti ed il controllo partendo da una prospettiva di costruzione di un nuovo modello di attuazione da parte del potere giudiziario. Quando parliamo di ambito, ci riferiamo alla definizione, alla ricerca del significato e della natura giuridica del diritto all'abitazione. I limiti, a sua volta, si riferiscono alla forma di introduzione di questo diritto nel nostro quadro normativo alla luce delle politiche pubbliche destinate alla sua concretizzazione e sistematizzazione nell'ambito del patto federativo.( si tenga presente il sistema federativo brasiliano). Finalmente, il controllo del diritto all'abitazione attraverso il potere giudiziario puo' essere ottenuto tanto con la mediazione, quanto con la giurisdizione. In paesi come il Brasile, dove esistono forti disuguaglianze sociali e le istituzioni democratiche si mostrano ancora fragili, le domande presentate agli agenti ed organi dello Stato, compresi quelli del potere Giudiziario, sono quantitativamente e qualitativamente maggiori se riferite alla concretizzazione dei diritti fondamentali. Cerchiamo, cosi, una riflessione sulla struttura giuridica e le politiche pubbliche abitative vigenti, cosi come sui meccanismi di utilizzazione di questa struttura per la soluzione delle vertenze giuridiche che arrivano nei tribunali. L'applicazione del diritto all'abitazione, secondo il nuovo ordine costituzionale e la legislazione corrente, vive ancora un processo di maturita' non completo. Si nota una difficolta' nella risoluzione di tali conflitti, che richiedono da parte dell'organo giudicante una nuova lettura dei principii costituzionali, soprattutto della funzione sociale della proprieta, anelando la concretizzazione del diritto sociale all'abitazione.

Parole chiave: Diritto all'abitazione; Funzione sociale della proprieta; Alloggio; Controllo giurisdizionale; Politiche pubbliche abitative. 


\section{SUMÁRIO}

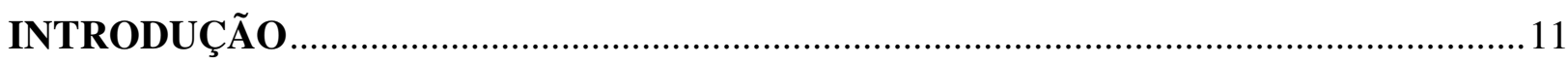

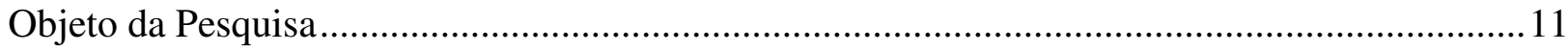

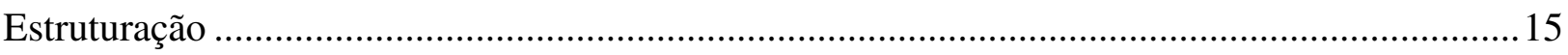

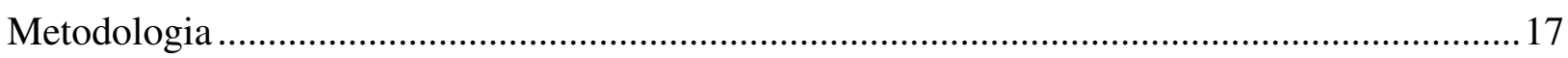

1. ÂMBITO DO DIREITO À MORADIA …………………………………………………18

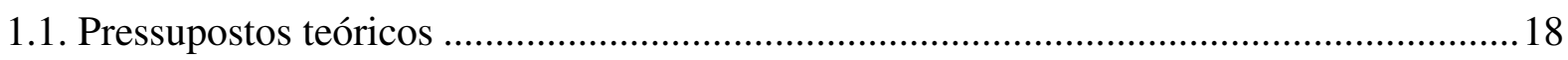

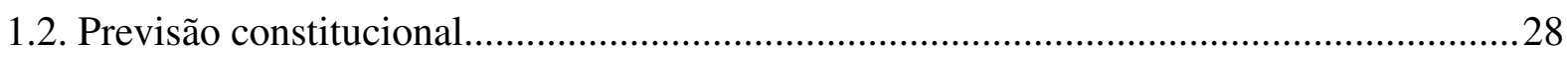

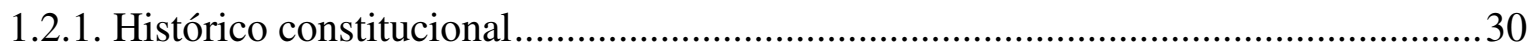

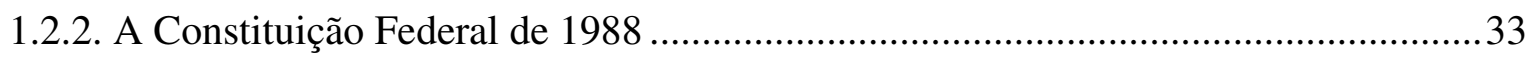

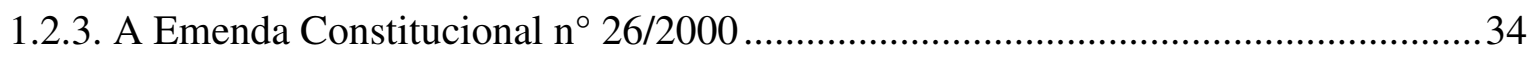

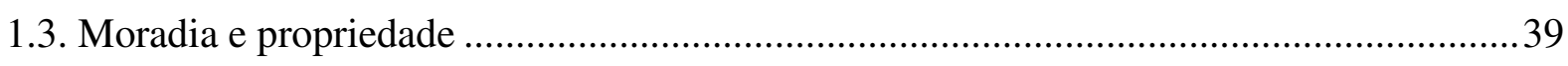

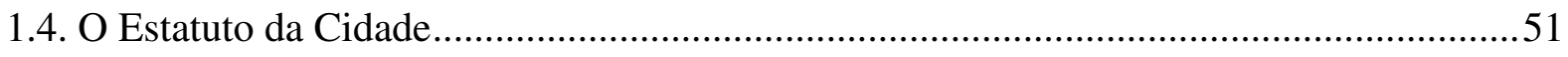

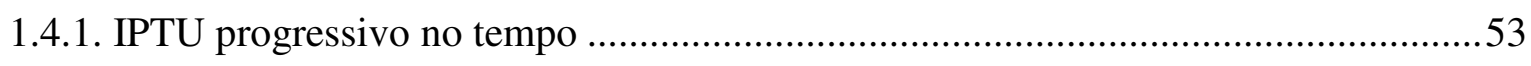

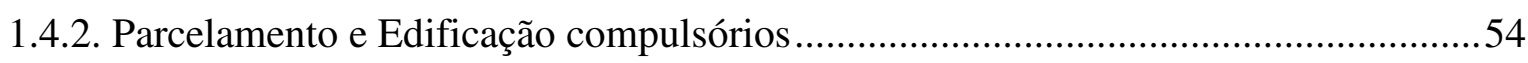

1.4.3. Usucapião especial de imóvel urbano …………………….....................................5

1.4.4. Zonas Especiais de Interesse Social (ZEIS) ………………................................55

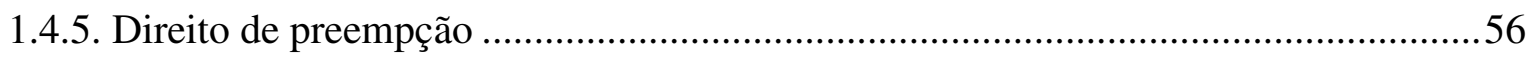

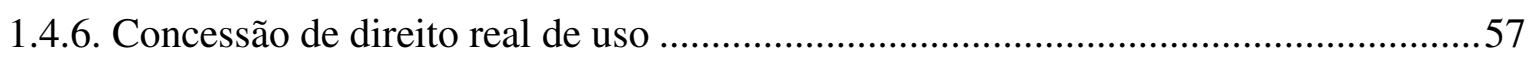

1.4.7. Concessão de uso especial para fins de moradia (CUEM) ..........................................57

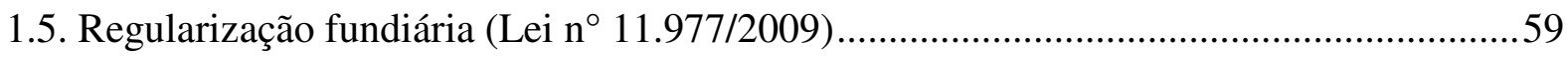

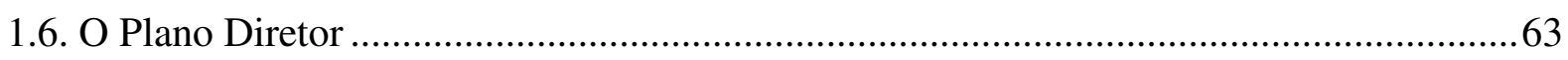

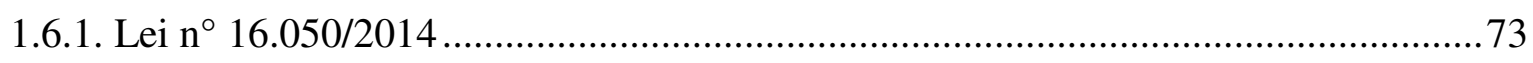

1.7. O direto à moradia no plano internacional ................................................................... 74

1.7.1. O Pacto Internacional de Direitos Econômicos, Sociais e Culturais...........................79

1.7.2. O Pacto Internacional sobre Direitos Civis e Políticos ...............................................83

1.7.3. A Declaração de Vancouver sobre Assentamentos Humanos......................................84

1.7.4. A Declaração de Istambul sobre os Assentamentos Humanos.....................................85

1.7.5. A Declaração sobre as Cidades e outros Assentamentos Humanos no novo

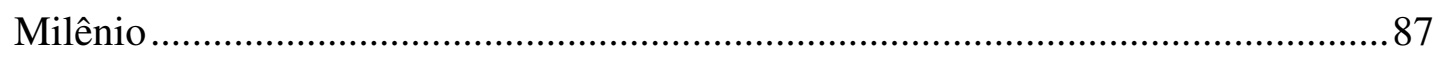

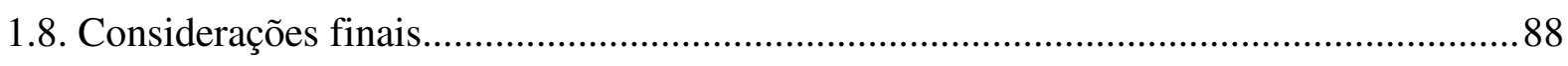

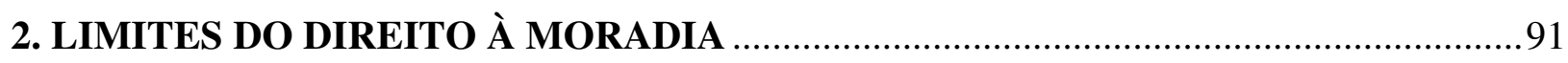

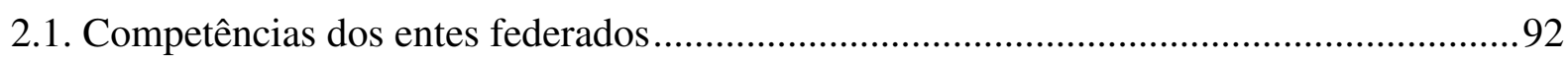

2.2. O papel do município como ente federado ………………………………………….......97 
2.3. Políticas públicas no Setor Habitacional …..................................................................... 104

2.3.1. Histórico das Políticas Públicas Habitacionais ....................................................... 106

2.3.2. Programa Minha Casa, Minha Vida ..................................................................... 118

2.4. A Política Nacional de Habitação .............................................................................. 125

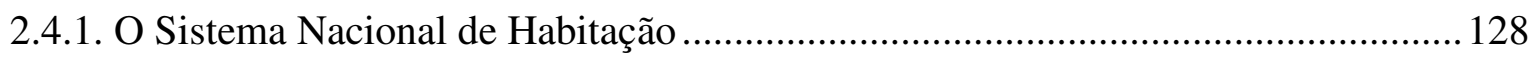

2.5. Subsistema de Habitação de Interesse Social.............................................................. 130

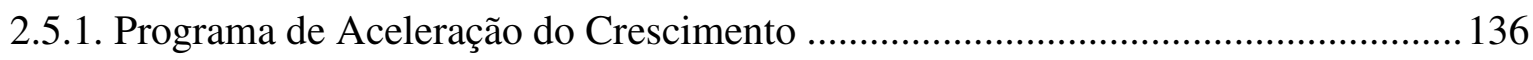

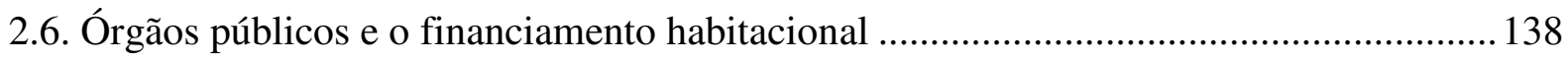

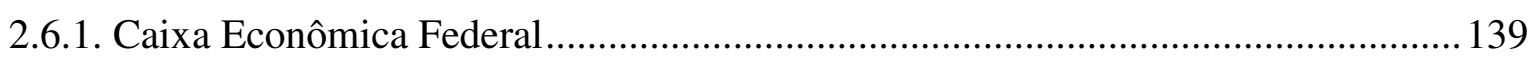

2.6.2. Companhia de Desenvolvimento Habitacional Urbano (CDHU) ........................... 140

2.6.3. Companhia de Habitação de São Paulo (COHAB/SP) ............................................ 142

2.7. Políticas habitacionais no Município de São Paulo ......................................................... 144

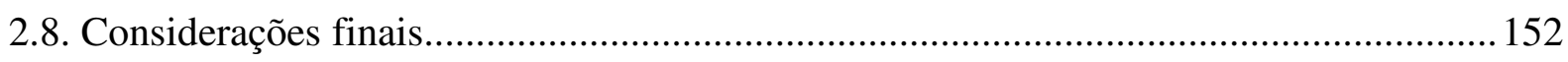

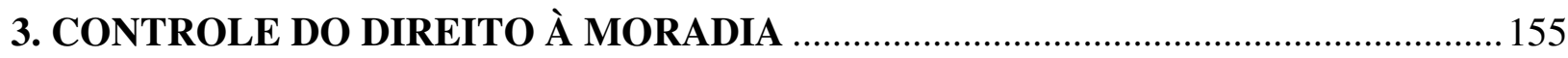

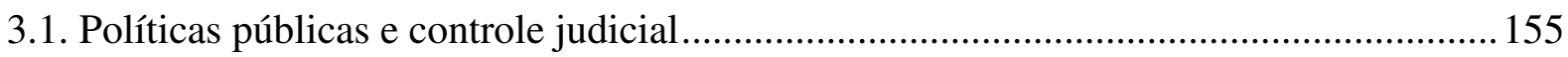

3.2. Ativismo judicial e função social do Poder Judiciário.................................................. 159

3.3. O direito à moradia no Poder Judiciário ...................................................................... 178

3.4. Direito à moradia no Tribunal de Justiça de São Paulo ................................................. 183

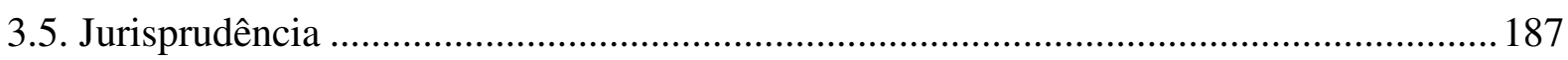

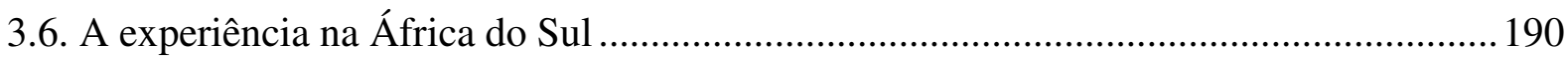

3.7. A mediação como instrumento do direito à moradia ................................................... 193

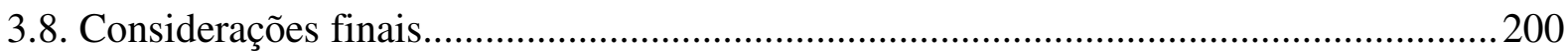

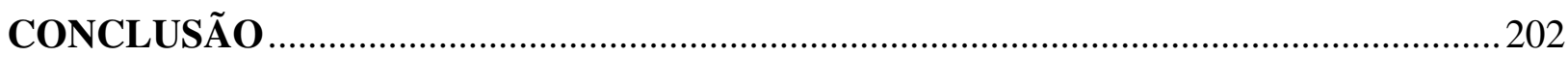

REFERÊNCIAS

ANEXO 


\title{
INTRODUÇÃO
}

\author{
"Há um tempo em que é preciso abandonar as roupas usadas, que já tem a \\ forma do nosso corpo, e esquecer os nossos caminhos, que nos levam sempre \\ aos mesmos lugares. É o tempo da travessia: e, se não ousarmos fazế-la, \\ teremos ficado, para sempre, à margem de nós mesmos" (Fernando Pessoa)
}

\section{Objeto da Pesquisa}

A escolha de um tema representa a tomada de posição do jurista diante de determinada problemática. A presente tese, intitulada de "Direito à moradia: âmbito, limites e controle no ordenamento jurídico nacional", tem por objetivo o estudo do direito à moradia e de sua inserção no ordenamento jurídico. Busca-se uma análise crítica de seu âmbito, de seus limites e de seu controle, dentro de uma perspectiva de construção de um novo modelo de atuação do Poder Judiciário, compatível com a ordem constitucional vigente.

A pergunta principal desta tese desdobra-se em duas indagações: o arcabouço jurídico existente em nosso ordenamento é suficiente para a solução dos conflitos judiciais envolvendo o direito à moradia? A análise do texto constitucional, dos diplomas legais em vigor e das políticas públicas sobre a matéria, ao longo desta tese, nos levou à uma resposta afirmativa. Diante desta constatação, uma segunda questão nos inquietou: como o Poder Judiciário brasileiro utiliza este arcabouço jurídico para a resolução dos conflitos relativos ao direito à moradia que chegam aos nossos tribunais? Neste sentido, entendemos que a aplicação do direito à moradia, de acordo com a nova ordem constitucional e a legislação decorrente, ainda está em processo de amadurecimento. Com efeito, nota-se uma enorme dificuldade na resolução de tais conflitos de acordo com os parâmetros tradicionais da decisão judicial, que sofrem limitações inerentes à dogmática normativa. Propõe-se, portanto, uma nova leitura deste arcabouço jurídico em harmonia com os princípios constitucionais, visando a concretização do direito à moradia.

Âmbito significa ambiente, campo, esfera ou contorno. Assim, a palavra faz referência à uma zona de atividade ou campo de atuação. No sentido específico desta tese, âmbito refere-se à definição, isto é, à busca do significado e da natureza jurídica do direito à moradia. O que significa, afinal, este direito? Sua natureza jurídica é de direito individual, social ou ambos? Como conciliar o direito à moradia com o direito de 
propriedade e o da proteção da posse em nosso ordenamento jurídico? Verifica-se, assim, que o enfrentamento do tema esbarra no desafio inicial de se definir o direito à moradia $\mathrm{e}$ de situá-lo na ordem jurídica vigente na hipótese de conflito com outros direitos igualmente protegidos pela ordem constitucional.

Os limites, por sua vez, podem ser compreendidos como balizas, linhas de demarcação, atribuições ou competências. Nesta tese, limites referem-se à forma de inserção do direito à moradia em nosso quadro normativo à luz das políticas públicas destinadas à efetivação e à sistematização deste direito no âmbito do pacto federativo. Neste diapasão, não raramente surgem dúvidas a respeito de quem é o ente público responsável pela elaboração das políticas de habitação. Assim, o que se pretende, quanto a tal aspecto, é uma abordagem dos principais programas habitacionais destinados à concretização do direito à moradia, ressaltando-se a importância da elevação do Município à categoria de ente federado. Diante da impossibilidade de se abordar todas as políticas públicas habitacionais, optamos por um recorte orçamentário, analisando-se as principais delas do ponto de vista da destinação dos recursos dos entes federados.

Finalmente, a questão do controle judicial, embora já bastante debatida na doutrina no que se refere à tutela de outros direitos sociais, merece tratamento mais cuidadoso no que diz respeito ao direito à moradia no Brasil, pois, diante de um conflito, individual ou coletivo, compete ao Poder Judiciário, em última análise, estabelecer as balizas necessárias para a solução do caso concreto.

Os dilemas práticos que envolvem esta temática são diversos. Ora, de que maneira o Poder Judiciário pode interferir na condução de políticas públicas urbanísticas para o atendimento do direito à moradia? Como conciliar os programas da Administração Pública com o ordenamento jurídico pátrio em caso de conflito? Como resolver os litígios em que há colisão entre o direito à moradia e o direito de propriedade, ou entre o direito à moradia e o meio ambiente, por exemplo?

Trata-se de tema que continua ganhando relevância acadêmica, pois as políticas públicas são efetivadas por meio da utilização de um conjunto de ações e projetos veiculados por normas jurídicas. Em países como o Brasil, onde há fortes desigualdades sociais e as instituições democráticas mostram-se ainda frágeis, as demandas levadas aos agentes e órgãos do Estado, dentre os quais estão os do Poder Judiciário, são quantitativas e qualitativamente maiores no que se refere à concretização dos direitos fundamentais. 
Durante a elaboração desta tese, foi possível notar que as políticas públicas urbanísticas destinadas à efetivação do direito à moradia, em muitos casos, padecem de grave problema institucional, a saber: as decisões do Poder Público nem sempre obedecem a uma racionalidade técnica, pois frequentemente atendem a pressões econômicas e interesses políticos particularistas ou imobiliários, o que agrava ainda mais os problemas nas cidades brasileiras.

A presente tese motivou-se na atuação em julgamento de conflitos que chegavam às Varas de Fazenda Pública da Capital de São Paulo e que envolviam o direito à moradia. Questões como a quem incumbe o direito de receber indenização nos processos de desapropriação, se ao proprietário, conforme determina a lei, ou ao possuidor que reside no local há muitos anos, passaram a ser cada vez mais frequentes na rotina jurisdicional. As dificuldades no julgamento de conflitos que envolvem o pedido de inclusão do cidadão em programas habitacionais, bem como as dúvidas em saber como as respectivas listas de atendimento mantidas pelo Poder Público são organizadas, passaram a exigir uma nova forma de atuação do juiz diante de conflitos relacionados ao direito à moradia.

O objetivo desta tese a partir do âmbito, dos limites e do controle jurisdicional do direito à moradia é, na realidade, tentar contribuir para o desenho institucional da política urbana brasileira, oferecendo uma interpretação dos princípios e institutos de direito urbanístico a partir de uma nova ordem constitucional compatível com o princípio da função social da propriedade.

Ora, a qualidade de vida dos centros urbanos está altamente deteriorada. Congestionamentos de veículos, desmoronamentos, enchentes, carência de infraestrutura e de equipamentos públicos, poluição sonora, visual, da água e do ar são apenas alguns dos infindáveis exemplos do desconforto a que se submete cotidianamente uma boa parte da população brasileira. ${ }^{1}$

Outrossim, dados do UN-Habitat revelam que mais de um bilhão de pessoas, isto é, um terço da população mundial, vivem em assentamentos precários e favelas, sem acesso a serviços básicos e sem condições de vida adequadas. O impacto dessas precárias condições de vida e a consequente falta de reconhecimento legal ou administrativo vão além da privação material e ambiental impostas aos moradores das favelas. Viver em

\footnotetext{
${ }^{1}$ PINTO, Victor de Carvalho. Plano diretor e direito de propriedade: contribuição para o desenho institucional da política urbana brasileira. 2001. Tese (Doutorado) - Programa de Pós-Graduação em Direito da Faculdade de Direito da Universidade de São Paulo, São Paulo, 2001. p. 4.
} 
assentamentos não regularizados deixa os moradores sem o usufruto de um amplo espectro de outros direitos humanos, civis e políticos, ou econômicos, sociais e culturais. ${ }^{2}$

A ocupação desordenada das cidades brasileiras como reflexo do êxodo rural e do início da industrialização a partir da década de 1930, em larga medida resultante da omissão do Poder Público no exercício de sua atividade fiscalizadora e promotora do desenvolvimento urbano e habitacional, contribuiu de forma decisiva para a situação de injustiça social vivenciada em inúmeros núcleos habitacionais, muitos dos quais caracterizados pela existência de franjas periféricas ocupadas pela população mais pobre, atraída pelo custo mais baixo dos imóveis. ${ }^{3}$

Vê-se, desta forma, que a disciplina urbanística, instrumento jurídico essencial à concretização do direito à moradia, reveste-se de vital importância, desenvolvendo-se juntamente com as cidades e seus cidadãos. Ora, nas palavras de TOSHIO MUKAI, "o fenômeno urbano, aqui e alhures, é constatado como um daqueles em que é preciso disciplinar e conformar para que o homem não se veja engolfado pela civilização do caos que se avizinha, na visão dos futurólogos e dos filósofos do nosso tempo". ${ }^{4}$

De fato, a ocupação e o desenvolvimento dos espaços habitáveis não podem ocorrer de forma meramente acidental, sob as forças dos interesses privados. Ao contrário, são necessários profundos estudos acerca da natureza da ocupação, sua finalidade, avaliação da geografia local, da capacidade de comportar essa utilização sem danos para o meio ambiente, de forma a possibilitar boas condições de vida para as pessoas, permitindo o desenvolvimento econômico-social e harmonizando os interesses particulares e os da coletividade. $^{5}$

Outrossim, a presente tese está inserida no contexto de um tema tradicional da teoria constitucional, que é o questionamento sobre a legitimidade de o Poder Judiciário para realizar reformas sociais, particularmente em relação às estruturas econômicas da sociedade.

\footnotetext{
${ }^{2}$ ROLNIK, Raquel. Direito à moradia. Desafios do Desenvolvimento, ano 6, ed. 51, 07 jun. 2009.

${ }^{3}$ LOPES, Roberta Castilho Andrade. A construção do direito à moradia no Brasil: da formação da norma à judicialização no Tribunal de Justiça do Estado de São Paulo. Tese (Doutorado) - Programa de Pós-Graduação da Faculdade de Arquitetura e Urbanismo da Universidade de São Paulo, São Paulo, 2014. p. 14.

${ }^{4}$ MUKAI, Toshio. Temas atuais de direito urbanístico e ambiental. Belo Horizonte: Fórum, 2004. p. 12.

${ }^{5}$ Id. Ibid., p. 29.
} 
Além desse fator, a solução dos problemas urbanos tende a ser analisada como um obstáculo exclusivamente político, que somente poderá ser resolvido mediante a eleição de melhores representantes pela população. Mudanças promovidas pelas urnas, contudo, serão insuficientes se não houver fortalecimento da ideia de planejamento urbano.

É preciso frisar ainda que esse quadro se repete em inúmeras cidades do país. É claro que as orientações políticas dos dirigentes têm profundo reflexo sobre as decisões tomadas sobre o desenvolvimento urbano. Todavia, enquanto não houver uma institucionalização abrangente do processo de planejamento, os métodos de gestão continuarão os mesmos, uma vez que serão as mesmas as pressões a que estarão sujeitos os dirigentes municipais. A alteração das instituições, embora mais lenta e trabalhosa, parece ser o principal caminho para que a função social da propriedade seja concretizada tal qual prevê nosso ordenamento jurídico.

O grande desafio no campo jurídico urbanístico no Brasil consiste em concretizar os objetivos previstos na legislação por meio de políticas públicas, as quais muitas vezes dependem da eficiente atuação do Poder Judiciário no respectivo controle jurisdicional.

\section{Estruturação}

O primeiro capítulo desta tese dedica-se ao âmbito do direito à moradia, com a análise de seus pressupostos teóricos e de sua proteção constitucional. Com esse enfoque, apresenta-se uma breve abordagem histórica das Constituições anteriores e a previsão do direito à moradia no Estatuto da Cidade, na Lei de Regularização Fundiária e Urbanística (Lei n 10.977/2009), no Plano Diretor e nos tratados internacionais. Com relação a estes últimos, adotamos o entendimento segundo o qual sua incorporação no ordenamento jurídico nacional depende da natureza jurídica, de modo que os tratados internacionais de direitos humanos ingressam em nossa ordem jurídica com status de norma constitucional, por força do que estabelece o art. $5^{\circ}$, parágrafos $1^{\circ}, 2^{\circ}$ e $3^{\circ}$, da Constituição Federal.

Os diplomas constitucionais e legais mencionados não esgotam a regulamentação do direito à moradia, também previsto, ainda que indiretamente, em outras leis. Optamos pela análise daquelas que tratam de modo mais específico deste direito, sendo mais frequentes nos litígios que chegam aos Tribunais.

O segundo capítulo, por sua vez, analisa as competências dos entes federados, o papel do Município no pacto federativo e as principais políticas públicas no setor 
habitacional, incluindo, também, a Política Nacional de Habitação, o Sistema Nacional de Habitação, o Subsistema de Habitação de Interesse Social e os Órgãos Públicos responsáveis pelo financiamento habitacional.

Este capítulo foi predominantemente elaborado a partir de documentos institucionais, com uso reduzido de bibliografia, pois o objetivo é fazer uma reflexão sobre as políticas públicas habitacionais e os projetos da Administração Pública que vigoraram e vigoram em nosso ordenamento.

O segundo capítulo, por abordar principalmente a disciplina financeira e orçamentária, está sujeito às limitações inerentes à área de concentração desta pesquisa, cujo enfoque se dá no campo dos direitos humanos. Contudo, mesmo ciente desta dificuldade, entendemos ser inviável a compreensão do conceito do direito à moradia e da forma como este direito é interpretado pelo Poder Judiciário sem se deparar com a complexidade das políticas públicas de habitação. Foi por esta razão, aliada à importância da interdisciplinaridade para um trabalho acadêmico, que dedicamos este tópico à análise do Sistema Nacional de Habitação, do Subsistema de Habitação de Interesse Social e dos Órgãos Públicos responsáveis pelo financiamento habitacional.

Finalmente, o terceiro e último capítulo dedica-se ao controle do direito à moradia pelo Poder Judiciário, seja por meio da mediação, seja por meio da jurisdição. Embora a mediação não se caracterize exatamente como forma de controle, pois não há imposição de sanção, há a presença de um agente intermediário na tentativa de solução da lide. Faz-se, num primeiro momento, uma breve abordagem do conceito de políticas públicas e de sua abrangência e, posteriormente, dos mecanismos de controle judicial de tais programas. $\mathrm{Na}$ sequência, analisam-se o ativismo judicial e a função social do Poder Judiciário na atualidade, bem como o direito à moradia à luz de alguns casos práticos. Em seguida, aborda-se a mediação como instrumento de realização do direito à moradia.

Assim, esta tese, do ponto de vista estrutural, está dividida nos três capítulos já mencionados. Seu fundamento assenta-se na própria existência dos direitos sociais, enquanto direitos constitucionalmente positivados, cuja nota distintiva é o fato de que sua concretização se dá por meio de prestações positivas do Estado. 


\section{Metodologia}

A metodologia utilizada, com base na análise da doutrina, enfatiza autores especializados em Direitos Humanos, Direito Constitucional e Direito Urbanístico. Assim, pretende-se analisar as políticas públicas urbanísticas à luz do ordenamento jurídico nacional, bem como os instrumentos para a concretização da função social da propriedade (Plano Diretor, políticas de financiamento da habitação e mediação em conflitos coletivos); e a história dos aspectos políticos, econômicos e sociais que influenciaram o debate sobre o controle jurisdicional de tal forma de atuação estatal.

Ainda sobre este aspecto metodológico, vale ressaltar que compartilhamos do enfoque proposto por Robert Alexy ${ }^{6}$ para o estudo dos direitos fundamentais no constitucionalismo democrático e social contemporâneo. Segundo este autor, o caráter da ciência do direito como uma disciplina prática, ao mesmo tempo conectada a posições morais, impõe a integração de três perspectivas da dogmática jurídica: além da dogmática normativa, que tem como propósito fornecer respostas adequadas a um determinado problema, há a dogmática analítica, que trata dos conceitos fundamentais e da estrutura do sistema jurídico, e a dogmática empírica, que é voltada ao conhecimento das dimensões que se manifestam no direito positivo, na prática jurisdicional e na verificação da eficácia dos direitos.

Ao se articularem as dimensões empírica, normativa e analítica da dogmática jurídica, evidencia-se que as opções políticas e legislativas nunca devem ser entendidas como meramente técnicas, mas como resultado do conflito de posições que se apoia em um amplo espaço de juridicidade dos princípios constitucionais. É nesse contexto que devem ser analisadas as opções hegemônicas de juridicidade presentes no atual impulso ao reconhecimento jurídico do direito à moradia.

\footnotetext{
${ }^{6}$ ALEXY, Roberto. Teoria dos direitos fundamentais. São Paulo: Landy, 2001.
} 


\section{CONCLUSÃO}

Esta tese se propôs a analisar o direito à moradia a partir de seu âmbito, seus limites e seu controle no ordenamento jurídico brasileiro.

A hipótese investigada desdobra-se em duas perguntas: o arcabouço jurídico existente em nosso ordenamento é suficiente para a solução dos conflitos judiciais envolvendo o direito à moradia? A análise do texto constitucional, dos diplomas legais em vigor e das políticas públicas sobre a matéria comprovou que a resposta é afirmativa.

Diante desta constatação, uma segunda questão foi formulada: como o Poder Judiciário brasileiro pode utilizar este arcabouço jurídico para a resolução dos conflitos relativos ao direito à moradia que chegam aos nossos tribunais? Neste sentido, percebemos que a aplicação do direito à moradia ainda está em processo de amadurecimento. Com efeito, nota-se uma enorme dificuldade na resolução de tais conflitos de acordo com os parâmetros tradicionais da decisão judicial, que sofrem limitações inerentes à dogmática normativa. Comprovamos, portanto, que a aplicação do direito à moradia pelo Poder Judiciário depende de uma nova leitura deste arcabouço jurídico em harmonia com os princípios constitucionais, devendo ser feita sobretudo por meio de ações coletivas e da mediação.

Quanto ao aspecto conceitual, o direito à moradia, apesar de mutável de acordo com o contexto histórico, apresenta natureza mista, isto é, de direito individual e social. Nesse sentido, apresenta uma dimensão de direito da personalidade, devendo o Estado protegê-lo em face de eventuais violações de terceiros. Da mesma forma, impõe ao Poder Público a necessidade de criação de políticas públicas para a sua concretização. A Constituição Federal de 1988, por meio da Emenda Constitucional $n^{\circ}$ 26/00, incluiu expressamente a moradia como direito social em seu art. $6^{\circ}$, estabelecendo que "são direitos sociais a educação, a saúde, o trabalho, a moradia, o lazer, a segurança, a previdência social, a proteção à maternidade e à infância, a assistência aos desamparados, na forma desta Constituição".

Esta natureza mista do direito à moradia o diferencia dos demais direitos sociais, na medida em que pode ser oponível tanto em face do particular, na hipótese de violação por terceiros, quanto em face do Estado, que deve criar políticas públicas para sua efetivação, bem como incluir o indivíduo ou grupo social vulnerável em programas habitacionais. A 
natureza mista, portanto, não se refere à titularidade processual do direito, isto é, à opção de ser exercido individual ou coletivamente, mas sim à sua forma de fruição, que pode se dar negativamente, para evitar violação por terceiros, ou positivamente, seja impondo ao particular a obrigação de dar à sua propriedade uma função social, ou à Administração Pública o dever de viabilizar o acesso à moradia.

Ademais, trata-se de um direito que somente pode ser efetivado pela fruição de uma moradia adequada, isto é, inserida em local habitável, garantida juridicamente e com acesso aos serviços públicos básicos.

Do ponto de vista da relação jurídica "indivíduo-Estado", é necessário esclarecer que o Poder Público deve criar programas e ações que atendam às necessidades dos cidadãos, criando condições para que os mesmos possam ter acesso à moradia, ao invés de provê-la diretamente. Por esta razão, não há, em princípio, um direito oponível diretamente ao Estado impondo que este forneça habitação ao indivíduo ou à comunidade que o pleiteia judicialmente. Encontram-se excetuadas as hipóteses de grupos sociais vulneráveis, que não tem condições, por si só, de ter acesso à moradia adequada. Nesta situação, deve o Poder Público incluí-los em programas habitacionais que viabilizem a efetivação do direito à moradia.

Ao longo desta tese, procuramos atentar para necessidade de distinção dos conceitos de moradia, propriedade e habitação, que por vezes são confundidos quando da elaboração de políticas públicas bem como quando do julgamento de conflitos judiciais. A moradia diferencia-se da propriedade pelo fato de a mesma representar uma necessidade intrínseca do ser humano, uma necessidade vital e, neste sentido, não uma escolha ou um direito intencional. A propriedade privada, ao seu turno, é um benefício, um direito de natureza patrimonial. Do mesmo modo, a moradia também se diferencia da habitação. Na primeira, a pessoa humana é o foco da tutela jurídica, independentemente de qualquer direito real ou pessoal. Já o direito à habitação incide sobre um bem imóvel como instrumentalização do direito à moradia, podendo ser gratuito ou oneroso, com caráter de direito real ou de direito pessoal.

Feitas essas considerações conceituais, podemos admitir que a Constituição Federal de 1988 conferiu uma nova dimensão ao direito à moradia, trazendo um Capítulo específico para a Política Urbana, com previsão da usucapião urbana, da função social da propriedade e da necessidade do Plano Diretor como instrumento da política de desenvolvimento. 
A Lei Federal $\mathrm{n}^{\circ}$. 10.257, de 10 de julho de 2001, denominada de Estatuto da Cidade e que regulamenta os artigos 182 e 183 do texto constitucional, por sua vez, inaugurou uma nova fase no tratamento do direito à moradia, contendo um rol de institutos jurídicos destinados à efetivação do princípio da função social da propriedade.

Em um segundo momento, a análise dos limites do direito à moradia revelou a importância da elevação do Município à condição de ente federado, com autonomia política, administrativa e financeira. A despeito das dificuldades existentes no tocante à efetiva autonomia municipal, a Constituição Federal de 1988 andou bem ao aproximar o debate sobre o direito à moradia da sociedade, tornando obrigatório o Plano Diretor e permitindo que cada Município atue em matéria urbana, de acordo com suas especificidades locais.

Também merece destaque a criação do Sistema de Habitação de Interesse Social pela Lei $\mathrm{n}^{\circ}$ 11.124/2005, integrando o Sistema Nacional de Habitação. Esse subsistema tem por objetivo viabilizar o acesso da população de menor renda à terra urbanizada e à habitação digna.

Dentro deste contexto, foi criado o Programa Minha Casa, Minha Vida, por meio da Lei $\mathrm{n}^{\circ} 11.977 / 2009$, visando justamente expandir o mercado habitacional nos extratos sociais de menor renda. Trata-se, atualmente, da principal ação governamental para redução do déficit habitacional.

Este programa representou uma ruptura em relação às práticas anteriores, por trazer a questão da habitação para o centro da agenda governamental, não somente pela escala de intervenção, mas também pelo volume de recursos empregados, pelas concessões de subsídios de até $96 \%$ para as camadas com renda de até $\mathrm{R} \$ 1.600,00$ e de subsídios parciais para as camadas de renda de até $\mathrm{R} \$ 5.000,00$, viabilizando o acesso à moradia para os setores de mais baixa renda, historicamente excluídos dos financiamentos para aquisição da casa própria.

Do ponto de vista do atendimento da demanda, verificamos que os beneficiados pelo programa pertencem às camadas sociais de menor renda que, na maioria das vezes, teriam dificuldade em acessar a moradia formal antes de sua existência.

Todavia, o que se constata da análise do Programa Minha Casa, Minha Vida, bem como do Sistema Nacional de Habitação de Interesse Social, é a existência de um modelo único de política habitacional. Ora, o Programa Minha Casa, Minha Vida não está 
destinado a garantir o direito à moradia, mas sim o direito de ter uma casa própria, que é uma das formas mais onerosas de se concretizar o direito à moradia. Além do custo do financiamento do imóvel, há a necessidade de o beneficiário arcar com os custos de condomínio e das tarifas de serviços públicos (água, luz, etc), resultando num índice alto de inadimplência.

Vale ressaltar, ainda, que os processos de seleção dos beneficiários feitos por meio de cadastros nem sempre são transparentes. Além disso, nota-se uma inadequação das alternativas ofertadas em relação às estratégias de moradia, especialmente em função da localização periférica das habitações, geralmente distantes das fontes de emprego da cidade.

A explosão da crise financeira e hipotecária, a política pública de subsídios para a compra de casas próprias, diretamente relacionada aos interesses do capital imobiliário, revelam a fragilidade deste modelo para a solução dos problemas relacionados ao direito à moradia.

De fato, o histórico das políticas nacionais para a habitação mostra como os principais programas transferiram ao setor privado o protagonismo na produção de habitações a serem financiadas, gerando uma distorção da política habitacional, na medida em que a efetivação dos direitos sociais é matéria que incumbe primordialmente ao Estado.

Ora, uma política habitacional de abrangência nacional, em um país de dimensões continentais, não pode ter como único objetivo a construção e a transferência de propriedade de novas unidades habitacionais. É preciso associar programas de urbanização de favelas e assentamentos precários, melhorias habitacionais, regularização fundiária, ocupação de áreas vazias e subutilizadas, recuperação de imóveis em áreas centrais para moradia social e, ainda, um programa de locação social para as famílias de menor renda, que não têm condição de arcar com os custos decorrentes da propriedade individual.

Deste modo, entendemos que, para uma melhor efetividade de nosso arcabouço jurídico, é fundamental garantir maior autonomia aos Municípios, bem como estabelecer políticas públicas que não se limitem à aquisição de casa própria, valendo-se de outros instrumentos jurídicos destinados à efetivação do direito à moradia.

Finalmente, no que tange ao controle, é possível dizer que os clássicos argumentos contrários à judicialização das políticas públicas, como o princípio da separação dos poderes, a reserva do possível e o déficit democrático, encontram-se atualmente superados 
no debate acadêmico. Há um certo consenso na doutrina constitucional contemporânea de que o princípio da separação dos poderes, a reserva do possível e o déficit democrático não podem servir de óbice à revisão das políticas públicas pelo Poder Judiciário, funcionando apenas como balizas para estabelecer o grau de intervenção judicial.

Neste diapasão, a Constituição Federal de 1988 e as profundas mudanças sociais e econômicas que marcaram o século XX passaram a exigir do Poder Judiciário uma nova forma de atuação, assumindo papel de protagonista na efetivação dos direitos sociais por meio da revisão de políticas públicas em ações de diferentes tipos.

Neste sentido, podemos citar como exemplos as hipóteses em que o programa governamental se revela insuficiente para atender às camadas sociais mais desfavorecidas, ou mesmo nos casos em que há uma omissão da Administração Pública, sendo necessária uma intervenção judicial para evitar que determinadas situações fáticas se perpetuem no tempo, como ocupações de imóveis públicos ou em áreas de risco.

No que diz respeito ao direito à moradia, objeto desta tese, mostra-se necessário estruturar o Poder Judiciário para que o mesmo analise os conflitos judiciais de acordo com esta nova ordem constitucional, que preconiza que a lógica civilista e patrimonialista deve ceder espaço à lógica da política constitucional urbana.

Isso porque se nota uma dificuldade na resolução das lides relativas ao direito à moradia de acordo com os parâmetros tradicionais da decisão judicial, que sofrem limitações inerentes à dogmática normativa. O Poder Judiciário apresenta características estruturais que muitas vezes acabam por restringir sua capacidade para promover mudanças sociais a partir de uma ótica distributiva, seja porque o juiz fica limitado ao pedido formulado ou às partes envolvidas no processo, que muitas vezes não refletem a dimensão social do conflito, seja pela ausência de informações necessárias para o julgamento do conflito, seja pela dificuldade de se discutir um direito social a partir de uma perspectiva unicamente individual.

Entendemos, portanto, que a efetiva proteção do direito à moradia pelo Poder Judiciário deve se dar, preferencialmente, por meio de ações coletivas ou da mediação.

O uso indevido de ações individuais como forma de transformação social pode gerar desigualdade, sobretudo no Brasil, onde a distribuição de recursos jurídicos é desigual. A hipótese de mediação, por sua vez, é uma nova forma de atuação judicial, 
caracterizada pela autocomposição entre os atores envolvidos com a participação do Estado-juiz.

A necessidade de se criar soluções pacíficas para a prevenção e resolução de conflitos relacionados à moradia vem ao encontro do surgimento de uma cultura da paz, evitando-se o uso da violência e as remoções forçadas, bem como à constituição de espaços de interlocução que permitam a tomada de decisão que considere as causas dos conflitos e seus possíveis desdobramentos.

A dificuldade do acesso à justiça dos moradores em habitações precárias cresce na medida em que falta ao Poder Judiciário estrutura e especialização para solução de conflitos fundiários, que representam um grande impacto social.

Todavia, aos poucos, mudanças vem sendo percebidas neste cenário. A existência de um arcabouço jurídico que regulamente o direito à moradia à luz da nova ordem constitucional, e as transformações, ainda que tímidas, ocorridas nos tribunais, conforme os julgados mencionados no capítulo 3.5 desta tese, acenam para um novo panorama.

Ainda temos muito a avançar em matéria de efetivação de direito à moradia, mas o fato é que a judicialização deste direito contribui para que o Poder Judiciário abra as portas para uma discussão entre as diversas instituições envolvidas no litígio, tais como o Ministério Público, a Defensoria Pública, a Administração Pública e os movimentos sociais.

Enfim, não há uma única resposta para esta problemática, pois, dos desafios que a presente tese logrou sugerir, é possível vislumbrar outros, a título de eventuais trabalhos futuros. Como, por exemplo, assegurar a efetivação do direito à moradia nas hipóteses em que sua violação não chega ao Poder Judiciário? Existem outras formas de se estruturar o Poder Judiciário para que o mesmo cumpra sua função na democratização da estrutura fundiária brasileira?

Com esta tese, procuramos responder aos dois questionamentos iniciais que constam da introdução: o arcabouço jurídico brasileiro é suficiente para a resolução dos conflitos judiciais envolvendo o direito à moradia, ainda que haja necessidade de seu aprimoramento, mostrando-se necessárias uma nova leitura deste ordenamento para sua efetiva concretização, bem como a estruturação do Poder Judiciário para a adequada pacificação dos conflitos fundiários. 
Ao mesmo tempo em que nosso ordenamento jurídico conta com a previsão de normas e princípios que regulam o direito à moradia, é o Poder Judiciário, em última análise, quem se apodera da decisão, indicando os rumos e as formas pelas quais as mudanças podem ser realizadas. 


\section{REFERÊNCIAS}

ACCA, Thiago dos Santos. Uma análise da doutrina brasileira dos direitos sociais: saúde, educação e moradia entre os anos de 1964 e 2006. Dissertação (Mestrado) Programa de Pós-Graduação em Direito da Faculdade de Direito da Universidade de São Paulo, São Paulo, 2009.

ALEXY, Roberto. Teoria dos direitos fundamentais. São Paulo: Landy, 2001.

ALMEIDA, Fernando Dias Menezes de. Considerações sobre os municípios no Brasil. In: TAVARES, André Ramos; FERREIRA, Olavo A. V. Alves; LENZA, Pedro (Coords.). Constituição Federal: 15 anos, mutação e evolução, comentários e perspectivas. São Paulo: Método, 2003.

Crítica ao tratamento constitucional do Município como ente da Federação brasileira. Revista de Direito Constitucional e Internacional, ano 17, n. 68, p. 76-85, jul./set. 2009.

ALVIM, Angélica A. Tanus Benatti; KATO, Volia Regina Costa; CASTRO, Luiz Guilherme Rivera de; ZIONI, Silvana Maria. Desafios das políticas urbanas no Brasil: a importância dos instrumentos de avaliação e controle social. Cadernos de Pós-Graduação em Arquitetura e Urbanismo, 2008. Disponível em: <http://www.mackenzie.br/dhtm/seer/index.php/cpgau/article/viewFile/109/16>.

ANSELMO, José Roberto, O papel do Supremo Tribunal Federal na concretização do federalismo brasileiro. 2006. Tese (Doutorado) - Pontifícia Universidade Católica, PUC/SP, São Paulo, 2006.

ARRETCHE, Marta Teresa Silva. Federalismo e políticas sociais no Brasil: problemas de coordenação e autonomia. São Paulo em Perspectiva, São Paulo, v. 18, n. 2, p. 17-26, 2004. Disponível em: <http://www.fflch.usp.br/dcp/assets/docs/Marta/ArretcheSPP2004.pdf>. Acesso em: 27 set. 2015.

; RODRIGUES Vicente (Orgs.). Política habitacional e descentralização no Brasil: a desarticulação de um novo modelo. In: DESCENTRALIZAÇÃO das políticas sociais no Brasil. São Paulo: Edições Fundap, Fapesp/IPEA, 1999.

(Coord.). Capacidades administrativas dos municípios brasileiros para a política

habitacional. Brasília: Ministério das Cidades; CEBRAP/Secretaria Nacional de Habitação, 2012. 
BELTRAMELLI NETO, Silvio. Amplitude das obrigações do empregador frente ao direito à moradia do trabalhador migrante. 2013. Tese (Doutorado) - Programa de PósGraduação em Direito da Faculdade de Direito da Universidade de São Paulo, São Paulo, 2013.

BLOCH, Janaína Aliano. O direito à moradia: um estudo dos movimentos de luta pela moradia no Centro de São Paulo. 2007. Dissertação (Mestrado) - Programa de PósGraduação em Direito da Faculdade de Filosofia, Letras e Ciências Humanas da Universidade de São Paulo, São Paulo, 2007.

BONDUKI, Nabil. Habitar São Paulo: reflexões sobre a gestão urbana. São Paulo; Estação Liberdade, 2000.

. Política habitacional e inclusão social no Brasil: revisão histórica e novas perspectivas no governo Lula. Revista Eletrônica de Arquitetura e Urbanismo, 2012. Disponível em: <http://www.usjt.br/arq.urb/numero_01/artigo_05_180908.pdf>.

BRUNO FILHO, Fernando Guilherme. Princípios de direito urbanístico. Porto Alegre: Sergio Antonio Fabris, 2015.

BUCCI, Maria Paula Dallari. Direito administrativo e políticas públicas. São Paulo: Saraiva, 2002.

BUENO, Cassio Scarpinella. Ação civil pública e Estatuto da Cidade. In: DALLARI, Adilson de Abreu; FERRAZ, Sérgio (Orgs.). Estatuto da Cidade: comentários à Lei Federal 10.257/2001. São Paulo: Malheiros Ed., 2001.

CAFRUNE, Marcelo Eibs. Inadimplemento do direito à moradia e legitimidade da ocupação: o caso Circo-Escola em São Paulo. Revista Direito e Práxis, v. 5, n. 8, 2014.

Mediação de conflitos coletivos fundiários urbanos: do debate teórico à construção política. Revista da Faculdade de Direito UniRitter, Porto Alegre, n. 11, p. 197-217, 2010.

CÂMARA, Jacintho Arruda. Plano Diretor. In: DALLARI, Adilson de Abreu; FERRAZ, Sérgio (Orgs.). Estatuto da Cidade: comentários à Lei Federal 10.257/2001. São Paulo: Malheiros Ed., 2001.

CAMPOS, Nubia Carla. A efetividade do direito à moradia no judiciário brasileiro: uma análise comparativa da jurisprudência. Monografia. Escola de Formação da Sociedade Brasileira de Direito Público, São Paulo, 2010.

CANOTILHO, José Joaquim. Direito constitucional e teoria da Constituição. 5. ed. Coimbra: Coimbra Ed., 1998. 
CARDOSO JR., José Celso et al. (Coord.). Estado, instituições e democracia: república. Projeto perspectivas do desenvolvimento brasileiro. Brasília: IPEA - Instituto de Pesquisa Econômica Aplicada, 2010. Livro 9, v. 1.

COMPARATO, Fabio Konder. Afirmação histórica dos direitos humanos. 2. ed. São Paulo: Saraiva, 2001.

CONTI, Jose Mauricio. Federalismo fiscal: questões contemporâneas. Florianópolis: Conceito Editorial, 2010.

Sistema constitucional tributário interpretado pelos tribunais. São Paulo: Ed. Oliveira Mendes, 1997.

; CARVALHO, André Castro. Direito financeiro e direito à morada: a concretização mediante a judicialização. In: DOMINGUES, José Marcos (Org.). Direito financeiro e políticas públicas. Rio de Janeiro: GZ Ed., 2015.

O CONSELHO Municipal de Habitação em São Paulo. Observatório dos Direitos do Cidadão, Instituto Pólis/PUCSP, set. 2002.

CORREIA, Fernando Alves. Estudos de direito do urbanismo. Coimbra: Almedina, 1998.

COSTA, Caio César Guerrera. Uma análise do setor imobiliário brasileiro de baixa renda: um estudo de caso do Programa Minha Casa, Minha Vida. 2014. Dissertação (Mestrado) Faculdade de Economia, Administração e Contabilidade da Universidade de São Paulo, Ribeirão Preto, 2014.

COUTINHO, Diogo R. (Coord.). O direito nas políticas públicas de habitação: usos de instrumentos urbanísticos no Município de Santo André, Brasil. Disponível em: $<w w w . s o c i o l o g i a j u r i d i c a . w o r d p r e s s . c o m>$.

DENIZO, Valentina. Os produtos da Política Estadual de Habitação na Região Metropolitana de São Paulo: elementos para análise de uma política metropolitana de habitação. Tese (Doutorado) - Programa de Pós-Graduação da Faculdade de Arquitetura e Urbanismo da Universidade de São Paulo, São Paulo, 2007.

DIREITO à moradia adequada. Brasília: Coordenação Geral de Educação em SDH/PR, Direitos Humanos, Secretaria Nacional de Promoção e Defesa dos Direitos Humanos, 2013. Disponível em: <http://www.sdh.gov.br/assuntos/bibliotecavirtual/promocao-edefesa/publicacoes-2013/pdfs/direito-a-moradia-adequada $>$.

DUGUIT, León. Manuel de droit constitutionnel: théorie générale de l'État, le droit et l'État, les libertés publiques, l'organisation politique de la France. Paris: E. de Boccard, 1923. 
FARIA, José Eduardo. Os desafios do Judiciário. Revista USP, São Paulo, n. 21, 1994. Disponível em: < http://www.revistas.usp.br/revusp/article/view/26935>.

O Judiciário e os direitos humanos e sociais: notas para uma avaliação da Justiça Brasileira. In: FARIA, José Eduardo (Org.). Direitos humanos, direitos sociais e justiça. 1. ed. São Paulo: Malheiros Ed., 1998.

FERNANDES, Edésio. Um novo estatuto para as cidades brasileiras. In: OSORIO, Letícia Marques (Org.). Estatuto da Cidade e reforma urbana: novas perspectivas para as cidades brasileiras. Porto Alegre: Sergio Antonio Fabris Editor, 2002.

(Org.). Direito urbanístico. Belo Horizonte: Del Rey, 1998.

FERREIRA, Luiz Paulo Teixeira. $O$ direito à moradia na Constituição Brasileira: o sistema de garantia na legislação e a experiência de São Paulo. 2006. Dissertação (Mestrado) - Programa de Pós-Graduação em Direito da Faculdade de Direito da Universidade de São Paulo, São Paulo, 2006.

FIGUEIREDO, Lúcia Valle. Disciplina urbanística da propriedade. 2. ed. São Paulo: Malheiros Ed., 1980.

FIORILLO, Celso Antonio Pacheco. Estatuto da Cidade comentado: Lei 10.257/2001. 3. ed. São Paulo: Ed. Revista dos Tribunais, 2008.

FRANÇA, Elisabete; COSTA, Keila Prado. Plano Municipal de Habitação: a experiência de São Paulo. São Paulo, 2012, v. 1. Disponível em: <http://www.habisp.inf.br/theke/documentos/pmh/2012/pmh_vol1_port/>.

GARCIA, Emerson. Ministério Público: organização, atribuições e regime jurídico. Rio de Janeiro: Lumen Juris, 2005.

GOMES, Wilson Luis da Silva. Articulações entre os setores públicos e privado em matéria urbanística. Tese (Doutorado) - Programa de Pós-Graduação em Direito da Faculdade de Direito da Universidade de São Paulo, São Paulo, 2013.

GOUVÊA, Carlos Portugal. Direitos sociais contra os pobres. Disponível em: $<$ http://www.law.yale.edu/documents/pdf/sela/SELA11_Gouvea_CV_Port_20110514.pdf>.

GRAU, Eros Roberto. O direito posto e o direito pressuposto. 4. ed. São Paulo; Malheiros Ed., 2002.

Direito urbano, regiões metropolitanas, solo criado, zoneamento e controle ambiental, projeto de lei de desenvolvimento urbano. São Paulo: Ed. Revista dos Tribunais, 1983. 
GRAU, Eros Roberto. A Ordem Econômica na Constituição de 1988. 7. ed. São Paulo: Malheiros Ed., 2002.

GRINOVER, Ada Pellegrini. O controle jurisdicional de políticas públicas. In: GRINOVER, Ada Pellegrini; WATANABE, Kazuo (Coords.). O controle jurisdicional de políticas públicas. Rio de Janeiro: Forense, 2011. p. 125-150.

HARADA, Kiyoshi. Direito urbanístico, Estatuto da Cidade e Plano Diretor estratégico. São Paulo: Ed. NDJ, 2005.

INSTITUTO POLIS. Disponível em: <www.polis.org.br>.

LIMA FILHO, Francisco das C. Garantia constitucional dos direitos sócias e a sua concretização jurisdicional. Revista do TRT da $24^{a}$ Região, n. 11, p. 19-54, 2006.

LOPES, José Reinaldo de Lima. Direito subjetivo e direitos sociais: o dilema do Judiciário no Estado Social de Direito. In: FARIA, José Eduardo (Org.). Direitos humanos, direitos sociais e justiça. 1. ed. 3. tir. São Paulo: Saraiva, 2002.

Direitos sociais: teoria e prática. São Paulo: Método, 2006.

LOPES, Roberta Castilho Andrade. A construção do direito à moradia no Brasil: da formação da norma à judicialização no Tribunal de Justiça do Estado de São Paulo. Tese (Doutorado) - Programa de Pós-Graduação da Faculdade de Arquitetura e Urbanismo da Universidade de São Paulo, São Paulo, 2014.

MACRUZ, João Carlos; MOREIRA, Mariana. O Estatuto da Cidade e seus instrumentos urbanísticos. São Paulo: LTr, 2002.

MEDAUAR, Odete; ALMEIDA, Fernando Dias Menezes de (Coords.). Estatuto da Cidade: Lei 10.257, de 10.07.2001: Comentários. São Paulo: Ed. Revista dos Tribunais, 2002.

MEIRELLES, Hely Lopes. Direito municipal brasileiro. 9. ed. São Paulo: Malheiros Ed., 1996.

MELLO, Celso Antonio Bandeira de. Novos aspectos da função social da propriedade no direito público. Revista de Direito Público, São Paulo, n. 84, out./dez. 1987.

MUKAI, Toshio. Temas atuais de direito urbanístico e ambiental. Belo Horizonte: Fórum, 2004.

NASCIMENTO, Luiz Alberto do. O déficit democrático do controle judicial de políticas públicas; 2013. Dissertação (Mestrado) - Programa de Pós-Graduação em Direito da Faculdade de Direito da Universidade de São Paulo, São Paulo, 2013. 
NASCIMENTO, Mariana Chiesa Gouveia. Regularização fundiária urbana de interesse social no direto brasileiro. Dissertação (Mestrado) - Programa de Pós-Graduação em Direito da Faculdade de Direito da Universidade de São Paulo, São Paulo, 2013.

OLIVEIRA, Fabiana Luci de; NUÑEZ, Izabel Saenger. Os direitos à moradia e à propriedade, um estudo de caso da regularização fundiária urbana em favelas cariocas. Direitos Fundamentais \& Justiça, ano 8, n. 26, p. 107, jan./mar. 2014.

PANNUNZIO, Eduardo. A judicialização das relações internacionais no Brasil em face do princípio constitucional da prevalência dos direitos humanos. 2012. Tese (Doutorado_) Programa de Pós-Graduação em Direito, Faculdade de Direito, Universidade de São Paulo, São Paulo, 2012.

PAUMGARTTEN, Michele Pedrosa. Constitucionalismo transformador: o caso sulafricano. Rev. SJRJ, Rio de Janeiro, v. 19, n. 34, ago. 2012.

PINTO, Victor de Carvalho, Direito urbanístico, plano diretor e direito de propriedade. 3. ed. São Paulo: Ed. Revista dos Tribunais, 2005.

Plano diretor e direito de propriedade: contribuição para o desenho institucional da política urbana brasileira. 2001. Tese (Doutorado) - Programa de Pós-Graduação em Direito da Faculdade de Direito da Universidade de São Paulo, São Paulo, 2001.

PIOVESAN, Flavia. Direitos humanos e o direito constitucional internacional. São Paulo: Max Limonad, 1997.

_. Tratados internacionais de proteção dos direitos humanos: jurisprudência do STF. Revista Internacional Direito e Cidadania. Disponível em: $<$ http://www.reid.org.br/arquivos/00000034-001_FlaviaPioveasn.pdf>. Acesso em: 20 out. 2015.

PIRES, Luís Manuel Fonseca. Moradia e propriedade: um breve ensaio sobre conflitos humanos. Belo Horizonte: Fórum, 2015.

RAMOS Geraldo Vinicius, CARDOSO, Álvaro Azevedo. Análise do Programa Minha Casa, Minha Vida, carta de crédito individual como financiamento de moradias para famílias de baixa renda. Disponível em: <www.aedb.br/seget/arquivos/artigos11/36114376.pdf>.

RANIERI, Nina Beatriz Stocco. Teoria do Estado: do Estado de Direito ao Estado Democrático de Direito. Barueri, SP, Manole, 2013.

REIS, José Carlos Vasconcellos dos. Os Municípios no Estado Federal brasileiro. Revista de Direito Administrativo, Rio de Janeiro, n. 228, abr./jun. 2002. 
RIOS, Andreia, PEREIRA; Isabel Kayser; BOTTA, Janaína; SILVA, Mariana Nunes da, IRACET, Mariza Aparecida Chuma; SOBREIRA, Rosmere Kalsing Zinn. Projeto Pacificar Mediação de Conflitos Fundiários Urbanos: entre a atividade extensionista e a construção da política urbana, Revista da Faculdade de Direito UniRitter, n. 11, p. 259$280,2010$.

RODRIGUES, Evaniza Lopes. A estratégia fundiária dos movimentos populares na produção autogestionária da moradia. 2013. Dissertação (Mestrado) - Programa de PósGraduação da Faculdade de Arquitetura e Urbanismo da Universidade de São Paulo, São Paulo, 2013.

RODRIGUES, Ruben Tedeschi. Comentários ao Estatuto da Cidade. Campinas; Millennium Ed., 2002.

ROLNIK, Raquel. Direito à moradia. Desafios do Desenvolvimento, ano 6, ed. 51, 07 jun. 2009.

SANTOS, Marília Lourido dos. Interpretação constitucional no controle judicial das políticas públicas. Porto Alegre: Sergio Antonio Fabris, 2006.

SAULE JR., Nelson. Estatuto da Cidade e o Plano Diretor: possibilidades de uma nova ordem legal urbana justa e democrática. In: OSORIO, Letícia Marques (Org.). Estatuto da Cidade e Reforma Urbana: novas perspectivas para as cidades brasileiras. Porto Alegre: Sergio Antonio Fabris, 2002.

et al. (Coords.). Sumário executivo relatório de pesquisa conflitos coletivos sobre a posse e a propriedade urbana e rural. Projeto "Pensando o Direito". São Paulo; Brasília: Pontifícia Universidade Católica de São Paulo, Centro pelo Direito à Moradia contra Despejos, Instituto Polis, 2009.

SILVA, José Afonso da. Curso de direito constitucional positivo. 24. ed. São Paulo: Malheiros Ed., 2005.

SILVA, Renata Gomes da. Relações entre os entes federados nas políticas públicas de habitação: uma análise do Sistema Nacional de Habitação de Interesse Social. 2014. Dissertação (Mestrado) - Programa de Pós-Graduação em Direito da Faculdade de Direito da Universidade de São Paulo, São Paulo, 2014.

SILVA, Rogério Florêncio da. Os direitos econômicos e sociais, a relação da eficácia do direito à moradia e o acesso à justiça, Dissertação (Mestrado) - Programa de PósGraduação em Direito, Faculdade de Direito, Universidade de São Paulo, São Paulo, 2013.

SILVA, Virgílio Afonso da. A constitucionalização do direito: os direitos fundamentais nas relações entre particulares. São Paulo: Malheiros Ed., 2011. 
SIQUEIRA, Guilherme Mello Ferraz de. Políticas públicas e direito urbanístico - papel do Poder Judiciário e ação civil pública. In: FREITAS, José Carlos de (Coord.). Temas de direito urbanístico. São Paulo: Imprensa Oficial do Estado; Ministério Público do Estado de São Paulo, 2000. v. 2.

SOBRANE, Márcia Alvarenga de Oliveira. A cidade e sua normatização constitucional. In: GARCIA, Maria (Coord.). A cidade e seu Estatuto. São Paulo: Juarez de Oliveira, 2005.

SUNDFELD, Carlos Ari. O Estatuto da Cidade e suas diretrizes gerais. In: DALLARI, Adilson de Abreu; FERRAZ, Sérgio (Orgs.). Estatuto da Cidade: comentários à Lei Federal 10.257/2001. São Paulo: Malheiros Ed., 2001.

Função social da propriedade. In: DALLARI, Adilson de Abreu; FIGUEIREDO, Lúcia Valle (Coords.). Temas de direito urbanístico. São Paulo: Ed. Revista dos Tribunais, 1987. v. 1.

ZANETI JR., Hermes. A teoria da separação de poderes e o Estado democrático constitucional: funções de Governo e funções de garantia. In: GRINOVER, Ada Pellegrini; WATANABE, Kazuo (Coords.). O controle jurisdicional de políticas públicas. Rio de Janeiro: Forense, 2011. 